\title{
elyra
}

REVISTA DA REDE INTERNACIONAL LYRACOMPOETICS

\section{A iluminação do Real: Mário Cesariny lê Vieira da Silva}

\author{
Maria Silva Prado Lessa \\ Universidade Federal do Rio de Janeiro
}

Resumo: Este artigo procura analisar a forma escolhida pelo poeta Mário Cesariny para abordar a obra da artista plástica Maria Helena Vieira da Silva no poema "ode a outros e a maria helena vieira da silva", a partir de cinco ensaios do poeta a respeito da artista. Nestes, Cesariny parece buscar uma forma justa para falar de sua obra plástica, algo que parece ser concretizado com a criação de uma linguagem poética que traga na sua própria estrutura, assim como os quadros de Vieira da Silva, uma reflexão sobre a realidade fragmentária vivida por ambos na Europa de meados do século XX. Na tentativa de passar a obra visual para outra linguagem, Cesariny se mostra comprometido com a percepção da realidade apresentada nas telas. A ode que compõe seria, portanto, uma possível resposta poética para o problema da representação na linguagem articulada.

Palavras-chave: Mário Cesariny, Vieira da Silva, fragmentação, colagem, representação

Abstract: This article explores the complicated structure created by the surrealist poet Mário Cesariny in the poem "ode a outros e a maria helena vieira da silva" in which he seeks to approach the visual work by the painter Maria Helena Vieira da Silva. Cesariny seems to combine different texts about Vieira da Silva written by him in different occasions. In these texts, it is possible to see how Cesariny is in search of a righteous form to approach the painter's canvas. He seems to succeed in his effort by conceiving a language that represents in its structure, the same way as the visual artist seems to do, a way to reflect upon the fragmentary reality experienced both by Cesariny and Vieira da Silva in mid-twentieth century Europe. In his attempt to transform visual work into a different type of language, Cesariny seems committed to Vieira's perception of reality.

Keywords: Mário Cesariny, Vieira da Silva, fragmentation, collage, representation 
O livro As mãos na água, a cabeça no mar (1985), de Mário Cesariny, reúne diversos textos de crítica literária e de artes visuais além de traduções, cartas e textos de intervenção do movimento surrealista português. Das muitas formas de expressão exploradas pelo artista no livro, destacam-se cinco escritos que parecem transitar entre diferentes registros: os textos referentes à obra da artista plástica franco-portuguesa Maria Helena Vieira da Silva.

A dedicação de Cesariny ao trabalho de Vieira da Silva, no entanto, não se limitou a esses trabalhos. O poeta contou com uma bolsa de estudos para investigar a obra da artista e de Arpad Szenes, seu companheiro. A pesquisa prolongou-se por vinte anos, de 1964 a 1984, tendo sido concluída com a publicação de Vieira da Silva / Arpad Szenes ou o Castelo Surrealista (1984). Assim, os textos anteriores à publicação que marcaria o encerramento dos seus estudos "formais" acerca da obra dos artistas plásticos parecem constituir ensaios de aproximação aos quadros de ambos, principalmente aos de Vieira da Silva. São eles: "Carta aberta a Maria Helena Vieira da Silva" (1952), "Passagem do Meteoro Vieira da Silva" (1957), “Da Pintura de Vieira da Silva" (1962), “A Pintura de Vieira da Silva e o Poético" (1970) e "34 Pinturas de Vieira da Silva" (1970). Os cinco textos apresentam a busca de Cesariny pela forma justa de se falar da obra da artista. Ao encontrarmos frases como "uma tela da Vieira da Silva é o amor do mundo glorificado" (Cesariny 1985: 88), podemos perceber certa tentativa de Cesariny de passar para a linguagem poética escrita a pintura já poética de Vieira da Silva, para além de criticá-la, estudá-la ou analisá-la. Assim, tais textos fogem à estrutura comum da crítica de arte, uma vez que parecem ser construídos a partir de fragmentos de outros textos, numa experimentação de diversas formas de se falar da criação plástica da artista.

Além desses escritos "teóricos", é dedicado um poema a Vieira da Silva e a "outros" publicado primeiramente em 19 Projectos de Prémio Aldonso Ortigão Seguido de Poemas de Londres (1971). Intitulado "ode a outros e a maria helena vieira da silva", o poema parece ser a forma por excelência encontrada por Cesariny para falar da obra de Vieira da Silva, uma vez que é somente através da criação de uma linguagem poética afastada da fala cotidiana e prosaica que se encontra a imagem poética de suas obras visuais. 
Cesariny parece questionar-se a respeito da legitimidade da linguagem articulada frente à imagem gráfica e da utilidade das palavras diante da potência da visão. Em uma conversa telefônica com Vieira da Silva, a artista Ihe pergunta: "como é possível falar sobre uma coisa que é para se ver?" (1985: 182). Seu interlocutor, em “A Pintura de Vieira da Silva e o Poético", afirma que

tal pergunta é uma crítica, severa, aos que usam e abusam de força de dialética ante o que é dado para contemplação, ou para a meditação silenciosa, que o próprio ato de pintar também é, e aplica-se certa a todo o uso abusado de substituição, de uma coisa por outra. (Cesariny 1985: 182)

A constatação de Cesariny pressupõe que há uma tendência, quando se fala sobre as artes visuais, a uma tentativa de substituição de um código por outro. A necessidade de contemplação à qual se refere o poeta apontaria para o reconhecimento da ineficácia das palavras frente à experiência no mundo e à experiência visual provocada pelas artes plásticas, algo que, por sua vez, é também tematizado e experimentado no trabalho poético de Cesariny. Há, portanto, a necessidade do silêncio: "a sua pintura obriga ao silêncio. Como escrever sob a sua pintura?" (idem: 182).

Tal questionamento a respeito da capacidade de se transpor a imagem de uma linguagem visual para a linguagem verbal parece estar ligado ao conceito de ekphrasis. Não seria possível, entretanto, relacionar o trabalho de elaboração da obra visual de Vieira da Silva empreendido por Cesariny à transformação em "verbal representation of visual representation" (Heffernan 1993: 3), uma vez que Cesariny reconhece como esforço impossível "respeitar-lhe a exigência [de meditação silenciosa] e, simultaneamente, prestar testemunho" (Cesariny 1985: 182). W. T. J. Mitchell, em "Ekphrasis and the Other" (1995), apresenta uma característica fundamental para se pensar sobre um texto escrito que pretende representar uma obra visual: a natureza representacional do objeto-fonte. Ao observarmos a obra de Vieira da Silva, percebemos que a representação em questão é, de fato, a de uma realidade fragmentária, de um real já transformado pelo olhar da artista. Assim, a dificuldade encontrada por Cesariny ao se propor a "falar sobre uma coisa que é para se ver" (Vieira apud Cesariny 1985: 182) estaria relacionada ao que define Mitchell 
como "indiferença ecfrástica" (1995: 152) que em Cesariny coincidiria com a crença de que a ekphrasis é impossível. Como afirma Mitchell,

\begin{abstract}
A verbal representation cannot represent - that is, make present - its object in the same way a visual representation can. It may refer to an object, describe it, invoke it, but it can never bring its visual presence before us in the way pictures do [Uma representação verbal não pode representar - ou seja, tornar presente - seu objeto da mesma forma que uma representação visual o faz. A representação verbal pode fazer referência a um objeto, descrevê-lo, invocá-lo, mas nunca trará sua presença visual diante de nós da mesma maneira que o fazem as imagens]. (Mitchell 1995: 152)
\end{abstract}

A constatação dessa impossibilidade poderia ser pensada nos termos da "utopia da linguagem" conforme apresentada por Barthes em Aula (s/d.). O semiólogo afirma que o que move a literatura é justamente a noção de que é impossível representar o "real" (s/d.: 22). Assim, a literatura se constrói no esforço constante em apreender uma totalidade inalcançável e plural e transpô-la a um registro unidimensional, a língua (idem: 21). 0 trabalho de Cesariny sobre a artista plástica, no entanto, parece apoiar-se no reconhecimento de que a representação em causa nas obras de Vieira da Silva recusa, de partida, a mimesis, ou a imitação daquilo que Barthes chama de "real". Logo, a representação nas telas da artista não estaria relacionada à tentativa de apreensão de um "real" total ou ao "desejo do impossível" (idem: 22) sobre o qual fala o francês, mas estaria, antes, comprometida em dar a ver a fragmentação dos espaços, da cidade e do próprio conceito de Realidade. Parece ser esta a dificuldade encontrada por Cesariny ao tomar para si o dever de falar sobre a obra de Vieira da Silva, encontrando-se, inevitavelmente, sob a obra, dominado e arrebatado por ela. Como, então, falar do indizível e da improvável natureza representacional dessa obra?

Talvez seja a incapacidade de apreensão do todo, incapacidade esta de tal modo presente nas telas de Vieira, o que o motiva a produzir os diferentes textos a seu respeito. Uma primeira análise dos escritos mostra que Cesariny os constrói a partir da montagem de diversas citações - sejam elas retiradas de seus próprios textos, sejam recortes de textos de outros -, porém utilizando sempre os mesmos fragmentos, de cada vez reorganizados e remontados. Isto é sentido a partir das repetidas referências a Rimbaud, ao xamanismo, a Baudelaire, ao também poeta surrealista António Maria Lisboa e aos próprios quadros de 
Vieira da Silva que se organizam de uma determinada maneira em um texto e reaparecem recortados e recolados ao longo das diferentes tentativas de abordagem da obra da artista.

A característica fragmentária dos textos de Cesariny parece estar em sintonia com a natureza fragmentária dos quadros de Vieira da Silva. A observação da tela "A Cidade Suspensa" (1952), a qual se encontra a seguir, revela uma fragmentação do espaço da cidade, sugerida já pelo título do trabalho: a "cidade" não apenas se encontra erguida e flutuante, mas interrompida, incompleta. Percebe-se, dessa forma, uma estrutura de cidade que teria sido fracionada e transfigurada. Assim, a pintora dá a ver as vigas dos edifícios reorganizadas e remontadas por ela. A fragmentação imposta ao espaço da cidade, ao cotidiano, é relacionada, por Cesariny, ao "poder visionário" (Cesariny 1985: 183) da poesia de Rimbaud, como vemos em “A Pintura de Vieira da Silva e o Poético" (1985 [1970]). Nesse texto, Cesariny afirma que "[s]obretudo nas sínteses de jardins e de aglomerados urbanos (entre tantas outras: [...] «A Cidade Suspensa» [...]) o paralelismo à visão-construçãodestruição rimbaldianas é [...] forte" (idem: 184). Em seguida, ao se referir a uma conversa que teve com a pintora, Cesariny recorda o fato de que "a impressionara duradouramente a reprodução de um quadro que representava "A Virgem e a Morte», a virgem, e o esqueleto - a estrutura de toda a construção. "Não a cor, a estrutura», acentuou Vieira, significando já toda a sua obra" (idem: 185).

O trabalho poético de Cesariny sobre (ou sob) a obra de Vieira dá a ver, por fidelidade à construção nela percebida, a sua estrutura. A fragmentação sugere um modo de fazer, um processo que é sentido conforme se lê - uma relação íntima entre o enunciado e a enunciação. Essa sensação se faz ainda mais forte quando o leitor encontra o poema "ode a outros e a maria helena vieira da silva", transcrito integralmente a seguir, para que se possa observar a fragmentação e colagem no discurso cesariniano. 


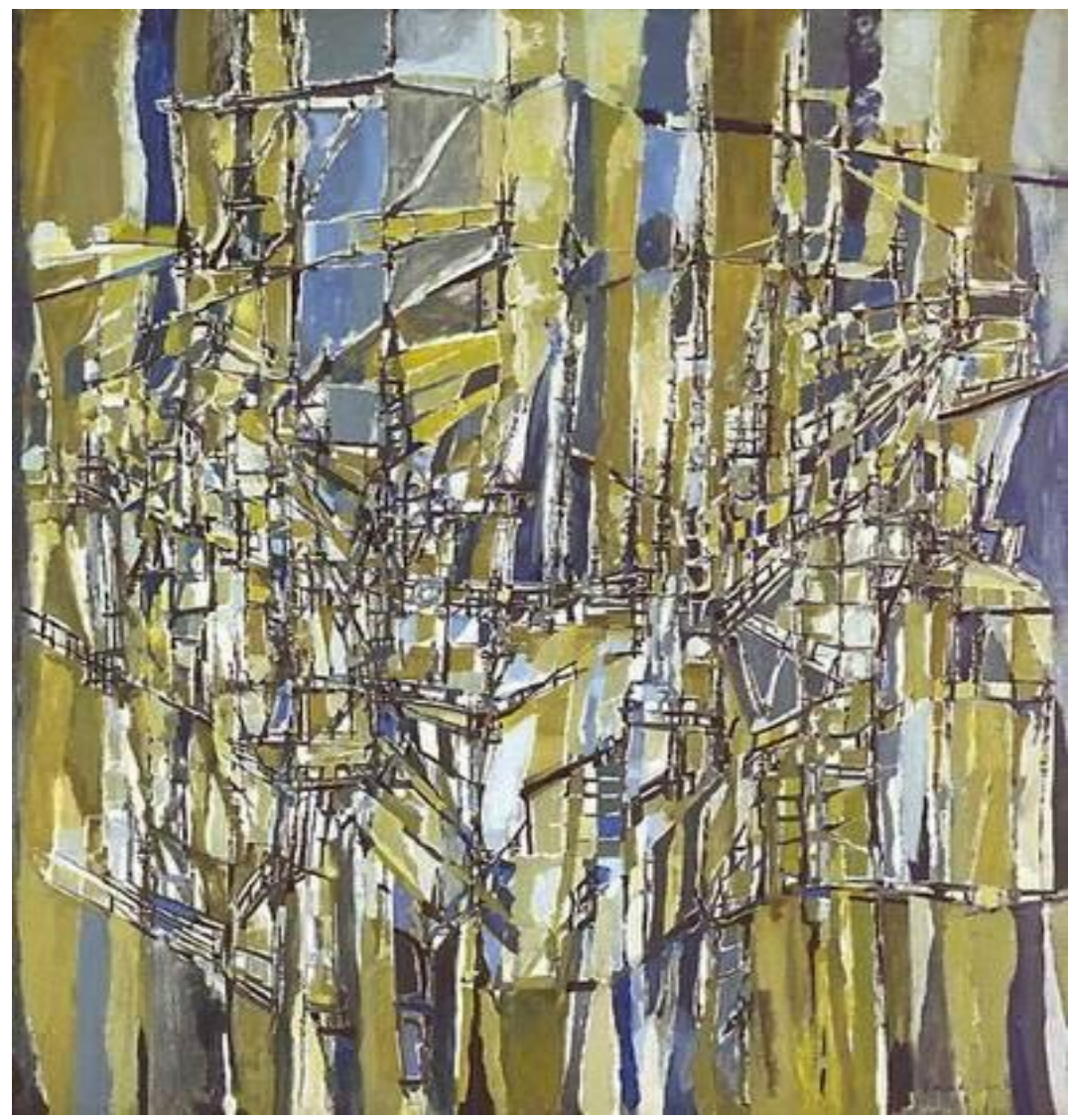

Maria Helena Vieira da Silva, “A Cidade Suspensa” (1952)

\section{ode a outros e a maria helena vieira da silva}

Sol de apaziguamento sol gelado

sol coberto de beijos só uma vez na neve

que começou a cair às quatro da tarde em Lausana

tinha eu acabado de arranjar hotel

às oito da noite em Grenoble

Era uma noite quente de princípio de estio

com uma cor de folha muito junta

as pessoas tomavam coisas era festa

eu tomava nos braços um poeta

que ia fugido em direcção a Marselha

de um auto-stop ia ele com uma mala

e que não nos fazia mais felizes

e depois fiquei só ao pé daquele rio

que falava espanhol sempre que lhe tocavam 
Tudo na Suíça! Tudo pela Suíça!

Anoitece e as primeiras idades do mundo

levantam a cabeça por cima de Évian

o próprio lago Léman

não é o que parece à primeira investida

a 30 de Fevereiro sob a névoa oferece

a paisagem perfeita de um oceano

um pouco mais pequeno que nature é certo

e um pouco mais ao norte também digo

mas só lhe chame lago quem não sabe

e eu soube-o há duas horas comovidamente

que dormem nele as presenças primeiras

do casamento do mundo

os primeiros ensaios da matéria

em direcção à boca actual do homem

Se to dissesse não acreditavas

mexe-se com um dedo ao de leve na pedra

e começa a aparecer

um pé vi eu capaz de esboçar de um só traço todas as telas sombrias de Rembrandt

uma pata preta com garras

vi também uma boca de orador antigo

com dentes do tamanho das tuas pernas

no dia em que a encontraram não longe do teatro

onde hoje toca Richter

levaram-na a correr para palácio

e instalaram o todo sob a vitrina

mas o resto daquilo ainda vaga nos mares

qualquer dia aparece e cai tudo para trás

Claro não surge sempre um soldado de César

ou um ferro totémico de Gilgamesh

(para quem não sabe: o primeiro herói lendário

que também era bicha ou o primeiro bicha

que também era herói; para quem não saiba)

mas todos podem levar qualquer coisa agradável

ou cristalina ou medonha 
vidro de bolso

tarso desirmanado

e os que não podem fumam e passeiam

o que ainda não é pequena maneira de ter

«A técnica por excelência xamânica consiste na passagem de um plano cósmico a outro. O xamã é detentor do segredo da ruptura dos níveis. Existem três grandes planos cósmicos ligados por um eixo central, o Pilar do Céu. Este eixo passa por uma "abertura", um "buraco", por onde o espírito do xamã pode subir ou descer em voos celestes ou descidas infernais.» Mircea Eliade

Que pena realmente o nosso excesso de mares

e o nosso realmente só querermos isso

que pena a praia abandonada às ondas

e a lua que não deu uma para a caixa

assim como fizemos nem os bichos quiseram

foram todos para a Suíça que é mais perto

mesmo do vácuo mais perto da morte branca mais limpos

(digo bichos decentes de vários metros de alto

porque ao cão e ao gato tanto se lhes dá)

A neve nos sapatos como uma barba

lembra-me o Gama dos livros de infância

Que chapéu que ele usava!

Então aquela Índia começava assim?

E o mar que nós fizemos só para ser ondeado?

Crianças de piroca grande a remexer na trave do infinito

Luís de Sousa Luiz Vaz de Almada Luiz Pacheco

depois da praia surgia o terror

e depois do terror a destruição

Tudo o que aniquilámos porque parecia nosso sem testemunhas

e era jovem dúctil como um corpo nu

que esburacámos vivo só porque tínhamos ferros para isso

e assim não ficou escrito nunca será lido

«Para os Esquimós, por exemplo, o Pilar do Céu é em tudo idêntico ao poste que colocam no centro das suas habitações.» Mircea Eliade

Por isso a tua Cidade Suspensa é toda a nossa história por contar 
o nó que nos cerca a garganta sabiamente o abriste sobre a tela

a negro e a vermelho a cinza e a branco silvestre

para sempre livres do dédalo nosso

mas como ele mudo silêncio do nosso silêncio

E todas as bibliotecas inundadas perdidas incendiadas

todas as quimeras onde houve gente e de que não resta pedra sobre pedra

o rosto ao lado de um rosto num portal antigo

por isso a tua Gare llimitada a que arrancaste portas e telhado para homens e mulheres

poderem sempre partir

e os infindáveis baralhos de cartas onde a cada momento interrogaste o destino

ó vieira das silvas dos teus cabelos

presos à dança da pedra e do ar

«A este propósito, lembraremos o mito de uma idade paradisíaca onde os seres humanos podiam facilmente subir ao céu e estabelecer relações familiares com os deuses. O simbolismo cosmológico da casa e a experiência xamânica da ascensão confirmam, sob outro aspecto, este mito arcaico. Eis como: depois da interrupção das comunicações fáceis que, no início dos tempos, havia entre o céu e a terra, certos seres privilegiados (e em primeiro lugar Vieira da Silva) continuam a poder efectuar a ligação dos planos superior e inferior. Da mesma maneira, os xamãs têm o poder de voar e de aceder ao céu através da "abertura central", enquanto para os outros mortais essa abertura serve unicamente para a transmissão de oferendas.» Mircea Eliade/ Mário Cesariny

Por isso a tua Cidade para Gatos onde Rimbaud terá sempre o seu quarto

e onde Cecília a Doce vai começar a abrir

os seus braços de vento misturado ao vento

por isso as tuas mãos traçando linhas à passagem contínua do navio

que fantasticamente flutua a teu lado

e o vale o vale imenso aberto a branco

onde para sempre a tua mão repousa

e onde um dia quem sabe tu também

minha rainha negra para um cavaleiro húngaro

minha «águia imperial rindo às dentadas»

para o mais obscuro coração da matéria

minha nossa senhora da vitória

que corre o espaço sem morada certa

Ofélia roubada a Hamlet Inês de Castro Szenes 


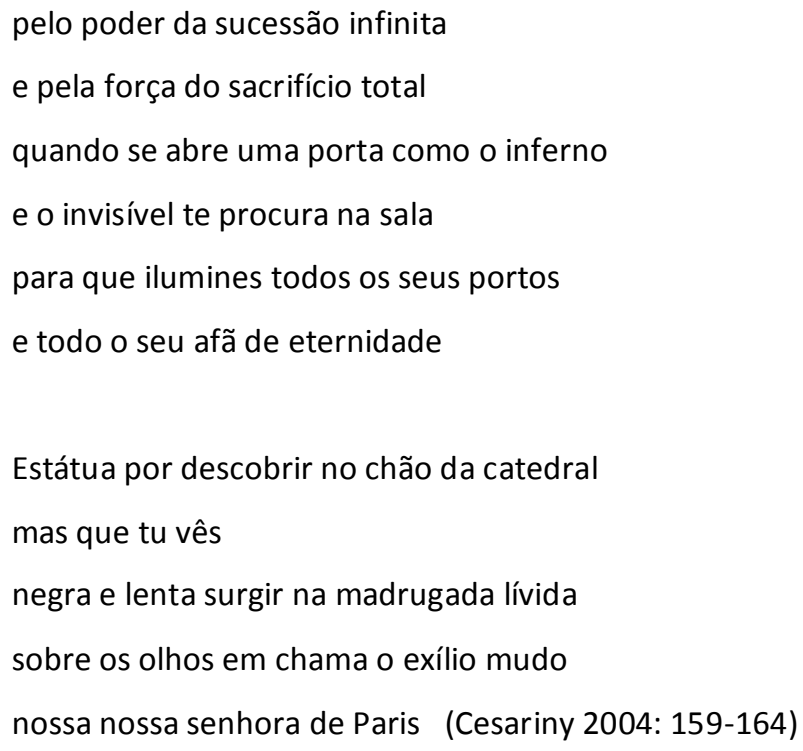

Apesar de longo, o poema vem aqui transcrito na íntegra para que se possa ter uma visão do "todo" construído pelo poeta. A omissão de qualquer trecho significaria impor uma fragmentação artificial ao seu corpo, o que acarretaria uma perda do significado que Cesariny parece dar ao esquema da colagem. Os cortes e colagens são vistos na interrupção da lógica de uma narrativa localizada no tempo e no espaço, na mescla entre experiência artística e experiência na realidade cotidiana, bem como na mistura de diferentes registros textuais, como é o caso da inserção de citações de Mircea Eliade a respeito do xamanismo e da "ruptura dos níveis" (Cesariny 2004: 161), colagens impactantes, também, por seu distinto caráter visual dentro do poema, uma vez que aparecem com recuo à direita, entre aspas e com indicações da autoria da passagem.

O primeiro corte pode ser sentido logo na primeira estrofe, quando surge um princípio de descrição narrativa frustrada pela falta de lógica temporal e espacial que a guiasse: "sol de apaziguamento sol gelado[...]/ que começou a cair às quatro da tarde em Lausana/ tinha eu acabado de arranjar hotel/ às oito da noite em Grenoble" (idem: 159). Em seguida, vemos outro corte na passagem da primeira para a segunda estrofe quando, logo após a descrição de uma noite fria e nevada, afirma-se que "[e]ra uma noite quente de princípio de estio" (ibidem).

Essas primeiras interrupções na lógica espaço-temporal levam a uma outra, referente à mistura entre os níveis de experiência no mundo. Nos versos "eu tomava no braço um poeta/ que ia fugido em direcção a Marselha" (ibidem), o poeta insere um novo plano de 
realidade - aquele criado pela arte. Nesses dois versos, podemos ver a evocação não apenas de Rimbaud enquanto homem, aquele que "ia fugido em direção a Marselha", mas Rimbaud enquanto metonímia de sua obra, que é levada pelos braços do eu-lírico. Nesse sentido, tal evocação é mais do que uma simples referência ao poeta, uma vez que insere no poema de Cesariny o próprio significado da obra do francês. A fragmentação espaço-temporal é fundida no encontro com a experiência artística em um espaço-tempo impossível, uma visita ao lago Léman, transformado em oceano, a "30 de Fevereiro" (Cesariny 2004: 159).

O espaço fundido é evidenciado, ainda, através das referências a outros artistas e personagens históricos que aparecem explicitamente nomeados: Rembrandt, Richter, César, Gilgamesh e Gama. As citações de Mircea Eliade inseridas no corpo do poema apontam, também, para esse espaço no qual se encontram todos os níveis de experiência. Apesar de inesperada, a "passagem de um plano cósmico a outro" (idem: 161) reservada aos xamãs e a "certos seres privilegiados" (idem: 163) é, de certa forma, a operação realizada por Cesariny no poema, já que promove uma "ruptura dos níveis" (idem: 161). Da mesma maneira parece fazê-lo a pintura de Vieira da Silva, conforme é sugerido na intervenção que faz Cesariny no trecho citado de Eliade: "«[...] certos seres privilegiados (e em primeiro lugar Vieira da Silva) continuam a poder efectuar a ligação dos planos superior e inferior. [...]» Mircea Eliade/ Mário Cesariny" (idem: 163).

Pode-se pensar, portanto, que Cesariny observa que a tentativa de representar a realidade cotidiana se dá através do empreendimento de um exercício fragmentário na obra de Vieira da Silva, o qual simultaneamente suspende a possibilidade de representação mimética, entendida como cópia do mundo visível. James Heffernan, em seu ensaio "Ekphrasis and Representation" (1991), ao se referir aos poemas de Keats “Ode on a Grecian Urn" e de Shelley, "Ozymandias", afirma que esses poetas "use these ekphrastic traditions to reflect on representation: not just on a particular work of graphic representation, but on the nature of representation itself" ["usam essas tradições ecfrásticas para refletir a respeito da representação: não apenas acerca de uma obra específica de representação gráfica, mas acerca da própria natureza da representação"] (Heffernan 1991: 304).

As pinturas de Vieira da Silva, então, parecem dizer algo a respeito das possibilidades de representação da situação de silenciamento e de aprisionamento do homem dentro de 
uma realidade absurda - as duas Guerras Mundiais, as ditaduras e o exílio. Tendo perdido sua cidadania portuguesa devido ao casamento com o húngaro Arpad Szenes, Vieira da Silva passou grande parte da vida em Paris e no Rio de Janeiro. Como afirma Luciana Lehmkuhl a respeito do casal, "[e]le apátrida por ser judeu húngaro, ela apátrida por ter com ele se casado e perdido, perante as leis portuguesas, o direito de cidadania" (Lehmkuhl s/d.: 1).

A invocação da realidade absurda é reconhecida no poema de Cesariny quando afirma, em referência ao quadro reproduzido anteriormente, "A Cidade Suspensa", "[p]or isso a tua Cidade Suspensa é toda a nossa história por contar/ o nó que nos cerca a garganta sabiamente o abriste sobre a tela" (Cesariny 2004: 162). Lemos, em seguida, referências diretas aos quadros de Vieira, como: "por isso a tua Gare llimitada a que arrancaste portas e telhados para homens e mulheres poderem sempre partir" (ibidem), e depois: "os infindáveis baralhos de cartas onde a cada momento interrogaste o destino" (ibidem).

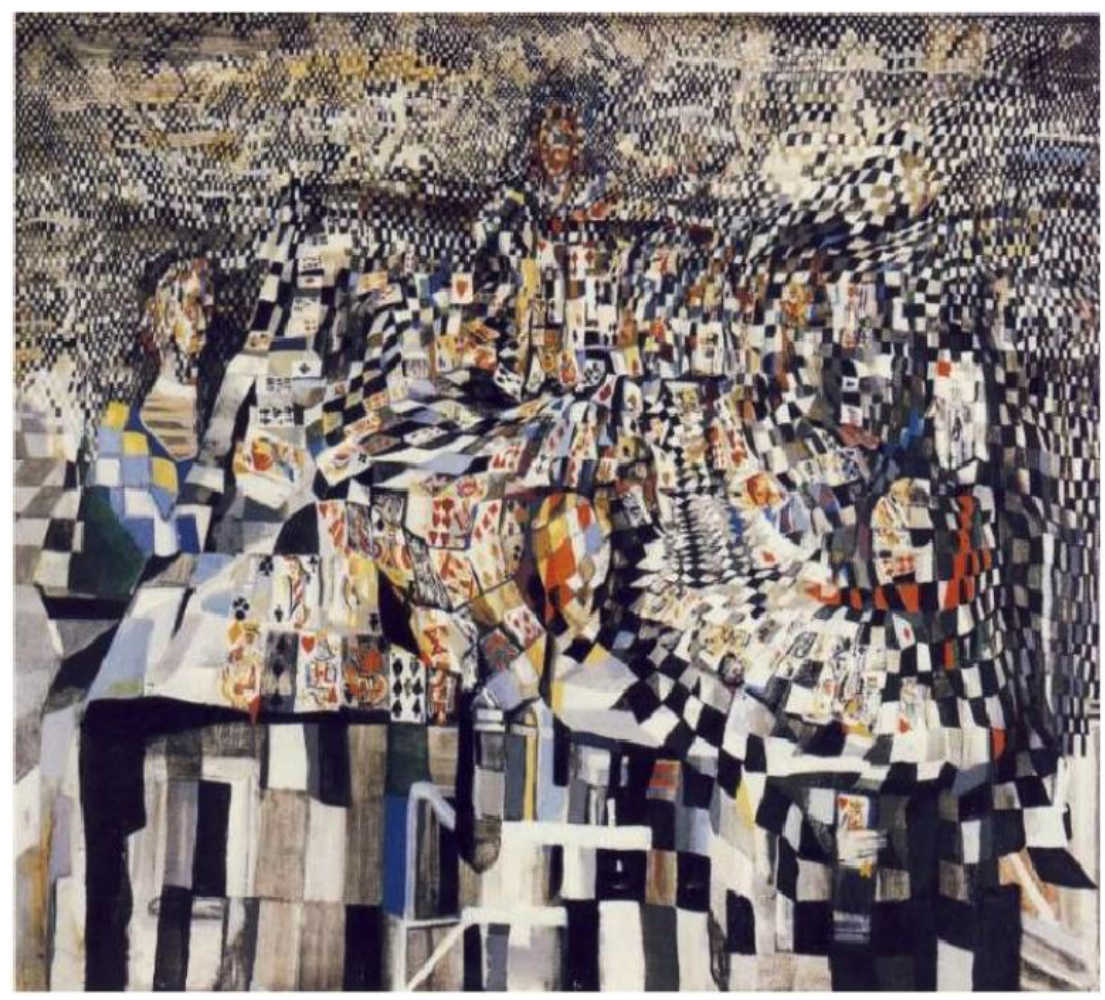

Maria Helena Vieira da Silva, “Os Jogadores de Cartas” (1947-1948)

A relação feita por Cesariny entre os quadros de Vieira e o real cotidiano aponta para uma percepção de que a arte é capaz de intervir na realidade. O "nó que nos cerca a 
garganta" (ibidem) é desfeito pela potência da tela; os "homens e mulheres [podem] para sempre partir" (ibidem) graças à criação de uma estação de trem sem barreiras; e o destino, por sua vez, só pode ser interrogado através da linguagem artística. Essa potência é sentida, também, na referência ao "poeta / que ia fugido em direcção a Marselha" (idem: 159) e que o eu-lírico cesariniano "tomava nos braços" (ibidem), o que modifica toda a percepção de um tempo linear dentro do poema e cria um espaço novo, no qual experiência de mundo e experiência artística se fundem, de forma xamânica.

A operação de corte e colagem empreendida por Cesariny reside em sua tentativa de desarticular o pensamento linear cronológico e narrativo dentro do poema. É a partir do "dom da invenção" (Cesariny 1985: 20) de uma profusão de imagens e da aparente confusão de referências, "pelo poder da sucessão infinita" (2004: 163), que se torna possível falar de "toda a nossa história por contar" (idem: 162).

O que se lê no poema de Cesariny, portanto, é uma ode à tentativa testemunhal/representativa daquilo que não se alcança através da experiência no cotidiano, daquilo que está interditado por um poder dominante. A arte seria uma forma de se alcançar esse invisível, esse impossível lugar fora das muralhas. Como afirma, "o invisível te procura na sala/ para que ilumines todos os seus portos/ e todo o seu afã de eternidade" (idem: 164). Essa característica testemunhal que Cesariny atribui à arte pode ser lida, também, nas referências às Navegações, a Os Lusíadas e ao épico Luís Vaz de Camões, representados pelo jogo feito em "Luís de Sousa Luiz Vaz de Almada Luiz Pacheco" (idem: 161), na metade do poema:

\footnotetext{
A neve nos sapatos como uma barba

lembra-me o Gama dos livros de infância

Que chapéu ele usava?

Então aquela Índia começava assim?

E o mar que nós fizemos só para ser ondeado?

Crianças de piroca grande a remexer na trave do infinito

Luís de Sousa Luiz Vaz de Almada Luiz Pacheco

depois da praia surgia o terror

e depois do terror a destruição

Tudo o que aniquilámos porque parecia nosso sem testemunhas
} 
e era jovem ductil como um corpo nu que esburacámos vivo só porque tínhamos ferros para isso e assim não ficou escrito nunca será lido (Cesariny 2004: 161-162; grifos meus)

Cesariny reconhece, assim, que a arte de Vieira da Silva se encontra em um plano superior da existência, no qual as antinomias "ter ou ser, haver ou imaginar" (Cesariny 1985: 186) são invalidadas, têm seus fundamentos arruinados (idem). Nesse sentido, relaciona sua arte simultaneamente ao movimento surrealista e ao romantismo alemão. A dissolução dos opostos, bem como o "reencantamento" do mundo, características fundamentais de ambos os movimentos, são apontados pelo poeta como elementos presentes na obra de Vieira. Sua forma de "ação" no mundo é o "poder obsessivo dos olhos sobre a tela" (Cesariny 1985: 185). Como sugere Cesariny, seria importante intuir

a que ponto extremo, inverossímil, mesmo, a inteligência do mundo é função dos olhos do pintor, dissociados, dir-se-ia, separados do apoio dos outros sentidos. A mão é o instrumento muito dócil, registador dos sismos e dos imponderáveis da visão. Dir-se-ia que tal obra [a de Vieira da Silva] não está, realmente, pintada, mas transmitida pelo poder obsessivo dos olhos sobre a tela (Cesariny 1985: 185).

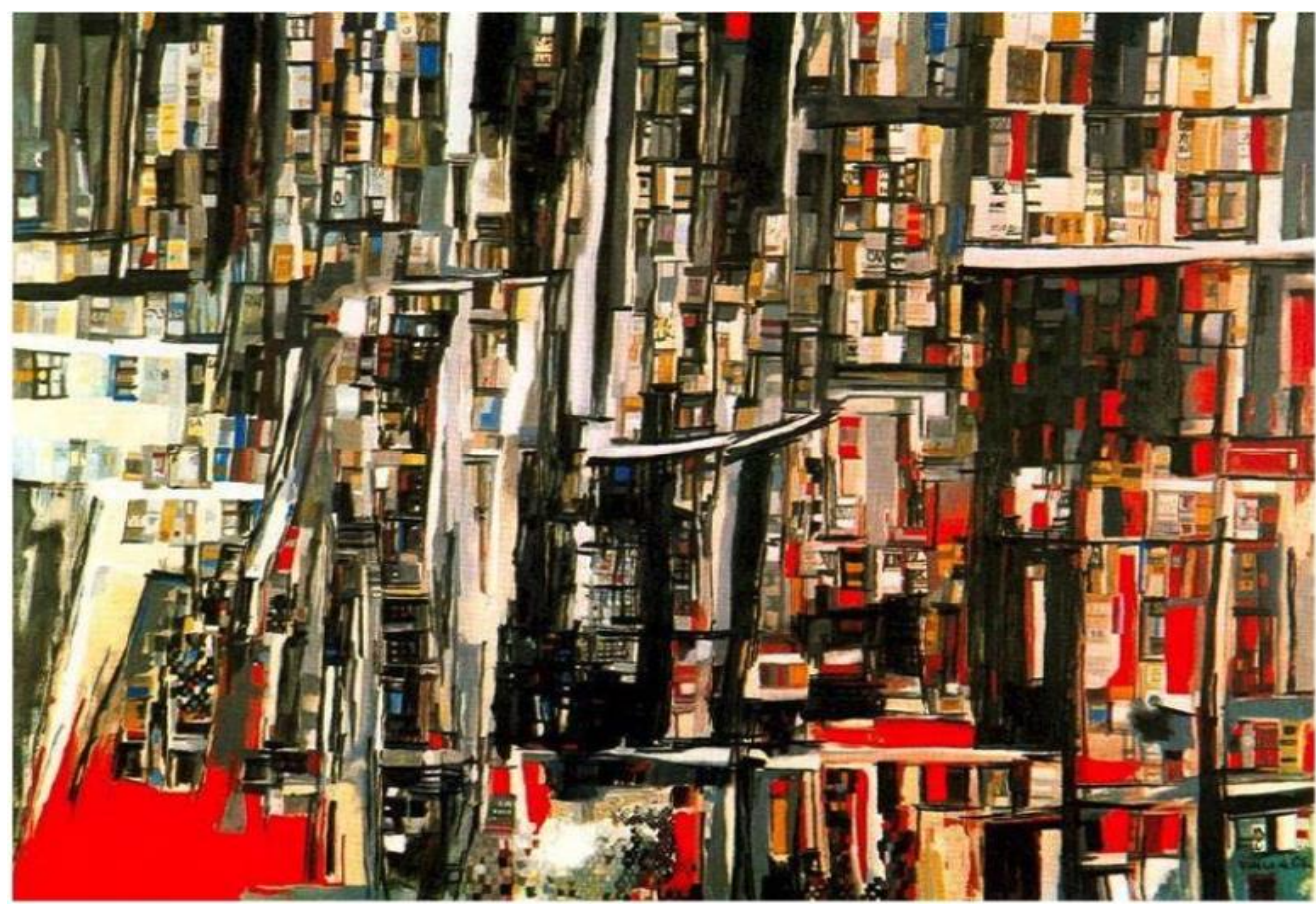

Maria Helena Vieira da Silva, “Biblioteca” (1955) 


\section{Bibliografia}

Barthes, Roland (s/d.), Aula, tradução de Leyla Perrone-Moisés, São Paulo, Cultrix.

Cesariny, Mário (1985), As mãos na água, a cabeça no mar, Lisboa, Assírio \& Alvim.

-- (2004), pena capital, Lisboa, Assírio \& Alvim.

Heffernan, James A. W. (1991), "Ekphrasis and Representation", New Literary History, Vol. 22, № 2, Probings: Art, Criticism, Genre, 297-316.

-- (1993), Museum of Words: The Poetics of Ekphrasis from Homer to Ashbery, Chicago e Londres, The University of Chicago Press.

Lehmkuhl, Luciene, "Imagens do exílio: Vieira da Silva no Brasil" < http://www.reseauamerique-latine.fr/ceisal-bruxelles/MS-MIG/MS-MIG-3-LEHMKUL.pdf > (último acesso em 09/11/2015).

Mitchell, W. J. T. (1995), "Ekphrasis and the Other", in Picture theory: essays on verbal and visual representation, Chicago, The University of Chicago Press.

Maria Silva Prado Lessa é mestranda bolsista (CNPq) do Programa de Pós-Graduação em Letras Vernáculas, na área de Literatura Portuguesa, da Universidade Federal do Rio de Janeiro (UFRJ). É bacharel em Letras: Português/Literaturas de língua portuguesa pela Universidade Federal do Rio de Janeiro (2014). 